\title{
Nuclear field shift effect of lead in ligand exchange reaction using a crown ether
}

\author{
By T. Fujii ${ }^{1, *}$, F. Moynier ${ }^{2}$, A. Agranier ${ }^{3}$, E. Ponzevera ${ }^{4}$ and M. Abe ${ }^{5}$ \\ ${ }^{1}$ Research Reactor Institute, Kyoto University, 2-1010 Asashiro Nishi, Kumatori, Sennan Osaka 590-0494, Japan \\ 2 Department of Earth and Planetary Sciences and McDonnell Center for Space Sciences, Washington University in St. Louis, \\ Campus Box 1169, 1 Brookings Drive, Saint Louis, MO 63130-4862, USA \\ 3 Institut Universitaire Européen de la Mer, Domaines Océaniques, UMR 6538, IUEM, Place Nicolas Copernic, 29820 Plouzané, France \\ ${ }^{4}$ Laboratoire de Géochimie et Métallogénie, Département Géosciences Marines, IFREMER, Z.I. Pointe du diable, BP70-29280 Plouzané, France \\ 5 Department of Chemistry, Graduate School of Science and Engineering, Tokyo Metropolitan University, 1-1 Minami-Osawa, Hachioji-shi, \\ Tokyo 192-0397, Japan
}

(Received November 25, 2009; accepted in revised form December 17, 2010)

\section{Lead / Isotope fractionation / Crown ether / \\ Solvent extraction / Nuclear field shift / Ab initio calculation}

Summary. Lead isotopes were fractionated by the liquidliquid extraction technique between an aqueous phase and a crown ether. After purification by ion-exchange chemistry, the ${ }^{207} \mathrm{~Pb} /{ }^{206} \mathrm{~Pb}$ and ${ }^{208} \mathrm{~Pb} /{ }^{206} \mathrm{~Pb}$ isotopic ratios were measured by multiple-collector inductively coupled plasma mass spectrometry (MC-ICP-MS). Isotope fractionations $>0.05 \%$ o have been found. The conventional equilibrium mass-dependent isotope effect estimated by an $a b$ initio calculation was smaller than the $\mathrm{Pb}$ isotope fractionation experimentally obtained. Conventional mass-dependent isotope fractionation is not a valuable explanation for our results . The nuclear field shift effect, which results from the isotopic change in the nuclear size and shape, was also estimated by an $a b$ initio method combined with a finite nucleus model. The nuclear field shift effect calculated was in agreement with our experimental results. Therefore, this study reports the first nuclear field shift effect of $\mathrm{Pb}$ in an equilibrium ligand exchange reaction.

\section{Introduction}

Lead has four stable isotopes, in which abundances of ${ }^{206} \mathrm{~Pb}$, ${ }^{207} \mathrm{~Pb}$, and ${ }^{208} \mathrm{~Pb}$, are affected by radiogenic decay of $\mathrm{U}$ and $\mathrm{Th}$. The isotope composition of $\mathrm{Pb}$ is hence one of the essential chronological information in geology [1]. The isotopic composition of an element also changes via chemical exchange reactions. This is because the equilibrium constant of a chemical exchange reaction corresponding to an isotope is slightly different from that to another isotope. The effect is called chemical isotope effect or simply, isotope effect.

The classic theory of isotope effect has been established by Urey, Bigeleisen, and Mayer [2,3]. The theory originates from the difference in the intramolecular vibrational energies of isotopologues. The theory predicts the mass-dependent isotope fractionation. The magnitude of

\footnotetext{
*Author for correspondence (E-mail: tosiyuki@ rri.kyoto-u.ac.jp).
}

isotope effect (isotope enrichment factor, $\varepsilon$ ) is proportional to $\delta m / \mathrm{mm}^{\prime}$, where $\delta m$ means the isotopic mass difference of masses $m$ and $m^{\prime}$ of two isotopes (prime represents the light isotope). Though it is small, isotope fractionation via chemical exchange reactions is possible even for heavy elements like U [4]. However, these isotopic fractionations of very heavy elements, like $\mathrm{Pb}$, are usually neglected in geochemistry.

The isotope effect found in heavy elements has frequently been larger than that expected by the classic theory. This is now recognized as the nuclear field shift effect [5-10]. The nuclear field shift effect, which results from the isotopic change in the nuclear size and shape, is clearer for heavy elements and it is recognized as the major origin of the mass-independent isotope fractionation in chemical exchange reactions [10]. The conventional mass-dependent theory has been extended to include correction terms to account for nuclear properties, especially nuclear size and shape $[5,6]$. In recent studies on geochemistry and environmental chemistry, the nuclear field shift effect attracts attentions as a possible origin of isotopic anomalies found in nature $[7,11,12]$. The effect via chemical exchange reactions may have accompanied the formation of these samples. In this context, laboratory scale experiments with highly precise analytical methods are needed to understand the mechanism of the nuclear field shift effect.

The nuclear field shift effect of lead is demonstrated in the present study. The isotope fractionation in a two phase distribution of $\mathrm{Pb}$ was studied, in which an aqueous solution and an organic solution were used. A macrocyclic compound called crown ether was selected as a complexation agent with $\mathrm{Pb}$. The isotope fractionation has been found in the solvent extraction of $\mathrm{Ca}$ by crown ethers [13]. A liquid-liquid extraction system composed of an organic solution containing dicyclohexano-18-crown-6 (DC18C6) or dibenzo-18-crown-6 (DB18C6) and of an aqueous solution of $\mathrm{CaCl}_{2}$ was used. This application was expanded to various elements $[10,14]$. We chose a similar system of the pioneering works $[10,13,14]$. The isotopic ratios of $\mathrm{Pb}$ were measured precisely by multiple-collector inductively 
coupled plasma mass spectrometry (MC-ICP-MS). Because of a mass-independent bias found for $\mathrm{Pb}$ isotopic analysis by thermal ionization spectrometry (TIMS) with the silica gel technique (see references in [15]), we did not use TIMS in the present study.

In order to check the validity of the isotope separation factor obtained, we performed the molecular orbital calculations for related $\mathrm{Pb}$ complexes. The isotope fractionation via intramolecular vibrations was estimated as the reduced partition function ratio (RPFR) of isotopologues. The contribution of the nuclear volume to the RPFR was also estimated by an ab initio method.

\section{Experimental}

Dicyclohexano-18-crown-6 (DC18C6, over 97\% purity) and 1,2-dichloroethane (over $99.8 \%$ purity) were products of Fluka Chemie GmbH. Hydrochloric acid (Merck $\mathrm{KGaA}$ ) of analytical grade was purified by distillation. Lead(II) chloride (99.999\% purity) was a product of SigmaAldrich, Co., Inc. $\mathrm{PbCl}_{2}$ was dissolved in $\mathrm{HCl}$ to create solutions, $0.035 \mathrm{~mol} \mathrm{dm}^{-3}$ (M) $\mathrm{Pb}(\mathrm{II})$ in various concentration of $\mathrm{HCl}$. The organic phase was $0.1 \mathrm{M} \mathrm{DC18C6}$ in 1,2-dichloroethane. A $3 \mathrm{~cm}^{3}$ aqueous solution and a $3 \mathrm{~cm}^{3}$ organic solution were mixed in a glass vial with a stirrer bar, and the glass vial was sealed. The two phases were stirred by a magnetic stirrer for $30 \mathrm{~min}$. After the extraction equilibrium was attained, the two phases were separated by centrifugation. An aliquot of the upper aqueous solution was taken for analysis. These procedures were carried out at $294.5 \pm 0.5 \mathrm{~K}$. The $\mathrm{Pb}$ concentration in the sample solution was analyzed by ICP-QMS (Agilent $7500 \mathrm{CX}$ ).

Organic impurities carried over the extraction were separated from $\mathrm{Pb}$ on anion exchange resin (AG1X8 200400 mesh) in $\mathrm{HBr} / \mathrm{HCl}$. The sample solution was dried up, and then dissolved into $\mathrm{HBr}$. This was dried up by heating once more, and then dissolved into $0.5 \mathrm{M} \mathrm{HBr}$ again. On the anion exchange resin in $0.5 \mathrm{M} \mathrm{HBr}, \mathrm{Pb}$ was strongly adsorbed while organic substances passed through freely. Finally, $\mathrm{Pb}$ was collected in $6 \mathrm{M} \mathrm{HCl}$.

The solutions of purified $\mathrm{Pb}\left(5 \mathrm{ppm}\right.$ in $0.3 \mathrm{M} \mathrm{HNO}_{3}$ ) were analyzed on a Neptune (Thermo Fisher) multiplecollector inductively coupled plasma mass spectrometer (MC-ICPMS) at the "Pole Spectrometrie Ocean" (PSO) of Brest. Isotopes ${ }^{206} \mathrm{~Pb},{ }^{207} \mathrm{~Pb}$, and ${ }^{208} \mathrm{~Pb}$, were analyzed on Faraday collectors. Because of the small abundance of ${ }^{204} \mathrm{~Pb}(1.4 \%)$, this isotope was not used for discussion. Solutions were spiked with Tl isotopic standard NIST997 (NIST, Gaithersburg, MD) to achieve $[\mathrm{Pb}] /[\mathrm{Tl}] \sim 10$ to correct for mass discrimination. The instrumental background was corrected for by measuring on peak zero signals.

\section{Computational details}

The molecular geometries and vibrational frequencies of aqueous $\mathrm{Pb}$ (II) species were calculated by using the density functional theory (DFT) implemented by the Gaussian 03 code [16]. The DFT method employed here is a hybrid density functional consisting of Becke's [17] three-parameter non-local hybrid exchange potential (B3) with Lee-Yang- and Parr (LYP) [18] non-local functionals. The 6-31+G** basis set (all-electron basis set) was chosen for $\mathrm{H}, \mathrm{O}$, and Cl. An effective-core potential (ECP) basis set, SDD, compensated the relativistic effect [19] was chosen for $\mathrm{Pb}$. These pseudopotential and basis sets were reported to be reliable for calculations of $\mathrm{Pb}$ species [20]. The SDD basis set including the $g$ function [21] was also tested.

As for the mass-independent isotope effect, the contribution of the nuclear volume was estimated by the DiracCoulomb Hartree-Fock (DCHF) method implemented in the UTChem program [22]. Calculations of the electronic structure of $\mathrm{Pb}^{0}\left([\mathrm{Xe}] 4 f^{14} 5 d^{10} 6 s^{2} 6 p^{2}\right), \mathrm{Pb}^{2+}\left([\mathrm{Xe}] 4 f^{14} 5 d^{10} 6 s^{2}\right)$, and a few simple $\mathrm{Pb}$ (II) molecules were performed. Exponents of basis sets are taken from Faegri's four-component basis for $\mathrm{Pb}$ [23], third-order Douglas-Kroll basis for $\mathrm{H}$ and $\mathrm{Cl}$ [24], and ANO-RCC for O [25]. Contraction coefficients is optimized by four-compoenent atomic calculations [26]. After we added some diffuse and polarization functions, the final contraction form of the large component basis sets is $(23 s 21 p 14 d 9 f) /[8 s 7 p 5 d 3 f]$ for $\mathrm{Pb},(16 s 11 p 1 d) /[4 s 3 p 1 d]$ for $\mathrm{Cl},(14 s 9 p 2 d) /[3 s 2 p 2 d]$ for $\mathrm{O}$, and $(8 s 2 p) /[3 s 2 p]$ for $\mathrm{H}$. More details are in the literature [9].

\section{Results and discussion}

Chemical species of $\mathrm{Pb}$ (II) in $\mathrm{HCl}$ media considered here are $\mathrm{Pb}^{2+}, \mathrm{PbCl}^{+}, \mathrm{PbCl}_{2}, \mathrm{PbCl}_{3}{ }^{-}$, and $\mathrm{PbCl}_{4}{ }^{2-}$, which are related through the following reactions,

$$
\begin{aligned}
& \mathrm{Pb}^{2+}{ }_{\text {aq }}+\mathrm{Cl}^{-} \rightleftarrows \mathrm{PbCl}^{+}{ }_{\text {aq }} \\
& \mathrm{PbCl}^{+}{ }_{\text {aq }}+\mathrm{Cl}^{-} \rightleftarrows \mathrm{PbCl}_{2 \text { aq }} \\
& \mathrm{PbCl}_{2 \text { aq }}+\mathrm{Cl}^{-} \rightleftarrows \mathrm{PbCl}_{3}{ }^{-} \text {aq } \\
& \mathrm{PbCl}_{3}{ }_{\text {aq }}+\mathrm{Cl}^{-} \rightleftarrows \mathrm{PbCl}_{4}{ }^{2-} \text { aq }
\end{aligned}
$$

The apparent stability constants of equilibria 1 to 4 have been summarized in the literature [27]. Fig. 1 shows the mole fractions of $\mathrm{Pb}$ species estimated by using the reported stability constants at ionic strength $4 \mathrm{M}$.

The anionic species are easily formed in $\mathrm{HCl}$ system. The fractions of $\mathrm{Pb}$ (II) species are switched as shown in Fig. 1. To avoid hydrolysis, our experiments were performed at high acidity region, $4.9-9.8 \mathrm{M} \mathrm{HCl}$, in which the anionic species are predominant in the system.

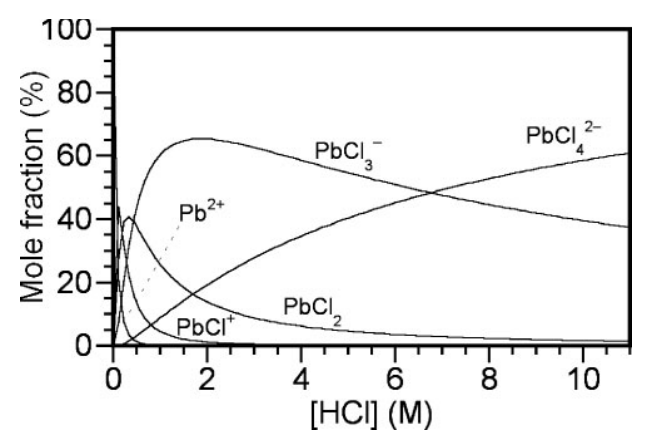

Fig. 1. Formations of the $\mathrm{Pb}(\mathrm{II})$ species in $\mathrm{HCl}$ solutions The mole fractions were calculated from the reported stability constants (apparent) [27]. The validity of mole fractions may be less precise at higher $[\mathrm{HCl}]$ region. 


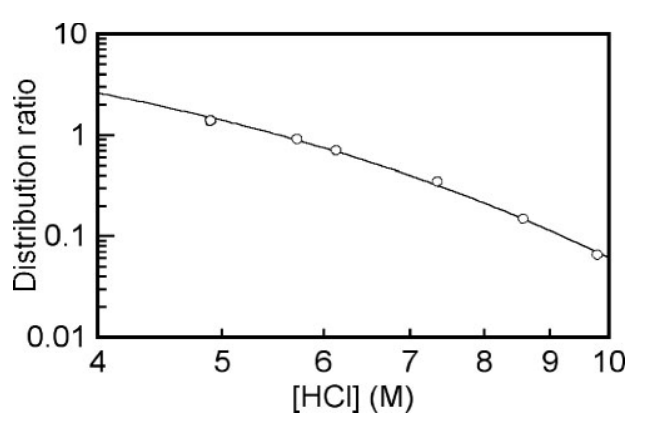

Fig. 2. Distribution ratio of $\mathrm{Pb}(\mathrm{II})$ as a function of $[\mathrm{HCl}]$.

A neutral ligand DC18C6 precedes ion association extraction, and hence the extraction reaction of $\mathrm{Pb}$ (II) may be written as,

$$
\mathrm{Pb}^{2+}{ }_{\text {aq }}+2 \mathrm{Cl}^{-}+\mathrm{L} \rightleftarrows \mathrm{PbLCl}_{2}
$$

where L stands for DC18C6. The distribution ratio,

$$
D=\Sigma[\mathrm{Pb}(\mathrm{II})]_{\mathrm{org}} / \Sigma[\mathrm{Pb}(\mathrm{II})]_{\mathrm{aq}}
$$

where subscripts org and aq mean the organic and aqueous phases, respectively, is shown in Fig. 2. The distribution ratio decreased with acidity. The formation of anionic species in the aqueous phase would have depressed the extraction of $\mathrm{PbCl}_{2}$. The decrease of $D$ may also be due to that the extraction of $\mathrm{HCl}$ consumed "free" crown ether.

The isotope separation factor $\alpha_{\mathrm{m}}$, between the aqueous and the organic phases, is defined as,

$$
\alpha_{\mathrm{m}}=\left(\left[{ }^{m} \mathrm{~Pb}\right] /\left[{ }^{206} \mathrm{~Pb}\right]\right)_{\text {org }} /\left(\left[{ }^{m} \mathrm{~Pb}\right] /\left[{ }^{206} \mathrm{~Pb}\right]\right)_{\mathrm{aq}}
$$

where the superscript $m$ indicates the mass of one particular isotope $(m=207$ or 208$)$. $\left(\left[{ }^{m} \mathrm{~Pb}\right] /\left[{ }^{206} \mathrm{~Pb}\right]\right)_{\text {org }}$ and $\left(\left[{ }^{m} \mathrm{~Pb}\right] /\left[{ }^{206} \mathrm{~Pb}\right]\right)_{\mathrm{aq}}$ are the isotopic ratios of ${ }^{m} \mathrm{~Pb}$ relative to ${ }^{206} \mathrm{~Pb}$ found in the organic and aqueous phases, respectively. In the present paper, we use $\delta$ notation, for which $\delta^{m} \mathrm{~Pb}$ is defined as,

$$
\delta^{m} \mathrm{~Pb}=\left(\alpha_{m}-1\right) \times 1000
$$

Since $\alpha_{m}$ is close to one, $\alpha_{m}-1$ is approximately equal to $\ln$ $\alpha_{m}$. Theoretically, logarithms of reduced partition function ratios (RPFRs) are used to derive $\ln \alpha_{m}$ [6].

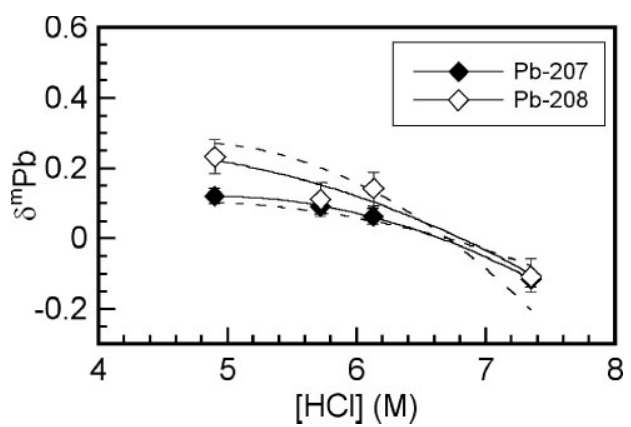

Fig. 3. $\delta^{m} \mathrm{~Pb}$ 's as functions of $[\mathrm{HCl}]$. Bold curves are quadratic curves fitted to the data. Dotted curves are quadratic curves fitted to the data ruled by a correlation, $\delta^{208} \mathrm{~Pb} / \delta^{207} \mathrm{~Pb}=\left(\left\langle r^{2}\right\rangle_{208}-\left\langle r^{2}\right\rangle_{206}\right) /\left(\left\langle r^{2}\right\rangle_{207}-\right.$ $\left.\left\langle r^{2}\right\rangle_{206}\right)$.
Table 1. Isotope fractionation of lead.

\begin{tabular}{lrr}
\hline$[\mathrm{HCl}](\mathrm{M})$ & $\delta^{207} \mathrm{~Pb}$ & \multicolumn{1}{c}{$\delta^{208} \mathrm{~Pb}$} \\
\hline 4.90 & $0.120 \pm 0.022$ & $0.233 \pm 0.048$ \\
5.72 & $0.092 \pm 0.022$ & $0.111 \pm 0.048$ \\
6.13 & $0.063 \pm 0.022$ & $0.142 \pm 0.048$ \\
7.35 & $-0.115 \pm 0.022$ & $-0.105 \pm 0.048$ \\
\hline
\end{tabular}

The $2 \sigma$ uncertainties of $\delta^{m} \mathrm{~Pb}$ are shown.

The $\delta^{m} \mathrm{~Pb}$ values obtained are shown in Table 1 . Analytical errors $(2 \sigma)$ of 8 replicates are shown together. Isotope fractionation observed was as large as a few sub \%o. The $\delta^{m} \mathrm{~Pb}$ values obtained are also shown in Fig. 3. $\delta^{m} \mathrm{~Pb}$ was found to decrease with acidity.

The classic theory of chemical isotope fractionation is based on the mass-dependent isotope effect via the isotopic difference in vibrational energies of isotopologues $[2,3]$. The isotope enrichment factor is proportional to $\delta \mathrm{m} / \mathrm{mm}^{\prime}$, where $\delta m$ means the isotopic mass difference of masses $m$ and $m^{\prime}$ of two isotopes (prime represents the light isotope). The conventional mass-dependent theory has been expanded by adding the nuclear field shift effect [5],

$$
\ln \alpha=\frac{h c}{k T} v_{\mathrm{fs}} a+\frac{1}{24}\left(\frac{\hbar}{k T}\right)^{2} \frac{\delta m}{m m^{\prime}} b
$$

where $v_{\mathrm{fs}}$ is the nuclear field shift, $a$ the nuclear field shift scaling factor, and $b$ the scaling factor for the conventional mass effect. $h$ is the Plank constant, $c$ the light velocity, $k$ the Boltzmann constant, and $T$ temperature. The nuclear field shift effect is recognized as the origin of the massindependent isotope fractionation in chemical exchange reactions [10]. The nuclear field shift is an isotope shift in orbital electrons [28]. This results from the isotopic difference in the nuclear size and shape. Different isotopes have the same number of protons, but they do not have the same distribution of protons in space. The nuclear charge distribution, which is usually represented as the mean-square charge radius $\left\langle r^{2}\right\rangle$, is affected by the number of neutrons in the nucleus. The nuclear charge distribution gives an electric field, and its isotopic difference shifts the atomic energy levels, also displacing the electronic molecular states. The nuclear field shift is not mass-dependent but is strongly related to the neutron configuration of nuclear structure. The nuclear field shift $v_{\mathrm{fs}}$ is proportional to the isotopic difference in the mean-square charge radius, $\delta\left\langle r^{2}\right\rangle$ [28].

Firstly, we estimated the magnitude of the conventional mass effect. In order to evaluate the respective strength of mass-dependent effects, we performed some quantum chemical calculations of the vibrational energies of the aqueous $\mathrm{Pb}$ (II) species. The structure of aqueous $\mathrm{Pb}$ (II) complex, which has 6,7 , or 8 ligands configuration, is under discussion [20]. A six-coordinated $\mathrm{PbCl}_{n}\left(\mathrm{H}_{2} \mathrm{O}\right)_{6-n}{ }^{2-n}(n=0$, $1,2,3$, or 4) was examined in the present study. The hydrated $\mathrm{Pb}\left(\mathrm{H}_{2} \mathrm{O}\right)_{6}{ }^{2+}$ with octahedral symmetry $\left(O_{h}\right)$ was calculated. $\mathrm{The} \mathrm{Pb}-\mathrm{O}$ bond length for water molecules was calculated to be $2.664 \AA$ which agreed with the reported value [20]. The hydration enthalpy was calculated in the same manner with a literature [29], which was calculated to be $\Delta H_{\text {hyd }}^{\circ}=360 \mathrm{kcal} / \mathrm{mol}$. This agreed with the reported 
$\Delta H_{\text {hyd }}^{\circ}$ [30-32]. Our calculation results present the validity of the calculation method.

The structures of $\mathrm{PbCl}_{n}\left(\mathrm{H}_{2} \mathrm{O}\right)_{6-n}{ }^{2-n}$ were optimized and then intramolecular frequencies of these species were calculated in order to evaluate $\delta^{m} \mathrm{~Pb}$. The isotope enrichment factor due to the intramolecular vibrations can be evaluated from the reduced partition function ratio (RPFR) [3], $\left(s / s^{\prime}\right) f$,

$$
\begin{aligned}
& \ln \left(s / s^{\prime}\right) f=\Sigma\left[\ln b\left(u_{i}^{\prime}\right)-\ln b\left(u_{i}\right)\right] \\
& \ln b\left(u_{i}\right)=-\ln u_{i}+u_{i} / 2+\ln \left(1-e^{-u i}\right) \\
& u_{i}=h v_{i} / k T
\end{aligned}
$$

where $v$ means vibrational frequency. The subscript $i$ stands for the $i$ th molecular vibrational level with primed variables referring to the light isotopologue. The isotope enrichment factor due to the molecular vibration can be evaluated from the frequencies $(v)$ summed over all the different modes. The RPFRs obtained for the isotope pair ${ }^{206} \mathrm{~Pb}-{ }^{208} \mathrm{~Pb}$ at $298 \mathrm{~K}$ were shown in Table 2. For $\mathrm{Pb}\left(\mathrm{H}_{2} \mathrm{O}\right)_{6}{ }^{2+}$, a $g$-function [21] was added into SDD to see a polarization effect of $g$ orbital of $\mathrm{Pb}$. It was marginal change in the RPFR. 12 water molecules were arranged in the second hydration sphere as reported for divalent transition metal ions [29]. The RPFR of $0.024 \%$ increased. The RPFRs showed magnitudes in the range of $0.151 \sim 0.218 \%$. The molecular orbital calculation and vibrational frequency analysis of a large crown complex, $\mathrm{PdLCl}_{2}$, might be possible by using highly performance calculation system, but there is no reference data of $\mathrm{PdLCl}_{2}$ structure in organic solvents for assessing the validity of calculation result. Though the structure of the $\mathrm{Pb}$ crown complex is not clear, a similar magnitude of the RPFR may be expected. $\delta^{m} \mathrm{~Pb}$ observed results from differences in the RPFRs of $\mathrm{Pb}^{2+}, \mathrm{PbCl}^{+}, \mathrm{PbCl}_{2}, \mathrm{PbCl}_{3}{ }^{-}, \mathrm{PbCl}_{4}{ }^{2-}$, and $\mathrm{Pb}-\mathrm{Crown}$ complex, and their mole fractions. From the data shown in Table 2, the maximum difference in the RPFRs is $0.067 \%$ o. This is much smaller than $\delta^{208} \mathrm{~Pb}$ 's shown in Table 1. This suggests that the conventional mass effect is not the major origin of $\mathrm{Pb}$ isotope fractionation in our experimental system.

Recent quantum chemical studies have adopted finite nucleus models into $a b$ initio methods [7-9]. Since the method needs high computer performance, calculations for a few simple molecules have only been performed at present [7-9]. In the present study, the total electronic energies at the ground states of $\mathrm{Pb}^{0}\left([\mathrm{Xe}] 4 f^{14} 5 d^{10} 6 s^{2} 6 p^{2}\right)$ and $\mathrm{Pb}^{2+}\left([\mathrm{Xe}] 4 f^{14} 5 d^{10} 6 s^{2}\right)$ were calculated for different isotopes with different nuclear charge radii. Calculations for a few simple $\mathrm{Pb}$ (II) molecules were also tested. The molecular structures were optimized by the similar method to
Table 2. Logarithm of the reduced partition function, $\ln \left(s / s^{\prime}\right) f$, for isotope pair ${ }^{206} \mathrm{~Pb}-{ }^{208} \mathrm{~Pb}$ at $298 \mathrm{~K}$.

$10^{3} \ln \left(s / s^{\prime}\right) f$

\begin{tabular}{ll}
\hline $\mathrm{Pb}\left(\mathrm{H}_{2} \mathrm{O}\right)_{6}{ }^{2+}$ & 0.185 \\
$\mathrm{PbCl}\left(\mathrm{H}_{2} \mathrm{O}\right)_{5}{ }^{+}$ & 0.218 \\
$\mathrm{PbCl}_{2}\left(\mathrm{H}_{2} \mathrm{O}\right)_{4}$ & 0.204 \\
$\mathrm{PbCl}_{3}\left(\mathrm{H}_{2} \mathrm{O}\right)_{3}{ }^{-}$ & 0.184 \\
$\mathrm{PbCl}_{4}\left(\mathrm{H}_{2} \mathrm{O}\right)_{2}{ }^{2-}$ & 0.151 \\
\hline $\mathrm{Pb}\left(\mathrm{H}_{2} \mathrm{O}\right)_{6}{ }^{2+a}$ & 0.184 \\
$\mathrm{~Pb}\left(\mathrm{H}_{2} \mathrm{O}\right)_{18}{ }^{2+b}$ & 0.209 \\
\hline
\end{tabular}

a: $g$-function was introduced in SDD for $\mathrm{Pb}$;

b: 12 water molecules were arranged in the second hydration sphere.

obtaine RPFRs. The root mean square radii $\left(\left\langle r^{2}\right\rangle^{1 / 2}\right)$ reported in the literature [33], that is, $5.4897\left({ }^{206} \mathrm{~Pb}\right), 5.4942\left({ }^{207} \mathrm{~Pb}\right)$, and $5.5010 \mathrm{fm}\left({ }^{208} \mathrm{~Pb}\right)$, were used in the calculation. The total energies calculated are shown in Table 3 in atomic units (a.u.).

The nuclear field shift effect ( $\left.K_{\mathrm{fs}}[5]\right)$ compared to a reference can be estimated as,

$$
\ln K_{\mathrm{fs}}=\frac{h}{k T}\left(\delta E_{\text {reference }}-\delta E_{\text {species }}\right)
$$

where $\delta E=E\left({ }^{m} \mathrm{~Pb}\right)-E\left({ }^{206} \mathrm{~Pb}\right)$. We set $\mathrm{Pb}^{2+}$ as a reference. The estimated values are shown in Table 4 . The nuclear field shift effect is attributable to the probability density of electrons at nucleus, and hence, drastic change in the electron configuration should cause a larger effect. As a drastic case, the nuclear field shift effect in the $\mathrm{Pb}^{0}-\mathrm{Pb}^{2+}$ redox reaction was estimated. We also estimated the magnitude of nuclear field shift effect in the complex formation of $\mathrm{Pb}^{2+}$ with $\mathrm{O}^{2-}, \mathrm{Cl}^{-}$, or $\mathrm{H}_{2} \mathrm{O}$. Note that our experimental system is a ligand exchange system of $\mathrm{Pb}$ (II) complexes, that is, $\mathrm{Pb}^{2+}, \mathrm{PbCl}^{+}, \mathrm{PbCl}_{2}, \mathrm{PbCl}_{3}{ }^{-}, \mathrm{PbCl}_{4}{ }^{2-}$, and $\mathrm{PbLCl}_{2}$. As shown in Table 4, the hydration was found to be less effective to create the nuclear field shift effect. The ion association of $\mathrm{Pb}^{2+}$ with $\mathrm{Cl}^{-}$resulted in $\sim 10$ times larger nuclear field shift effect than the hydration case. Though it is smaller than that of the $\mathrm{Pb}^{0}-\mathrm{Pb}^{2+}$ redox case, the ligand exchange between $\mathrm{H}_{2} \mathrm{O}$ and $\mathrm{Cl}^{-}$created competing magnitude of the effect. The covalent bonding of $\mathrm{Pb}^{2+}$ with $\mathrm{O}^{2-}$ resulted in the largest effect and this was larger than the $\mathrm{Pb}^{0}-\mathrm{Pb}^{2+}$ redox case.

In the aqueous phase, the ligand exchange reactions between $\mathrm{H}_{2} \mathrm{O}$ and $\mathrm{Cl}^{-}$have taken place. From the data shown in Table 4, the nuclear field shifts of $0.108 \%$ ofor ${ }^{207} \mathrm{~Pb}$ and $0.269 \%$ or for ${ }^{208} \mathrm{~Pb}$ are expected for this ligand exchange reaction. The magnitudes cover all $\delta^{m} \mathrm{~Pb}$ values, and hence, the

Table 3. Total energy of $\mathrm{Pb}^{0}$ and $\mathrm{Pb}^{2+}$ isotopes and $\mathrm{Pb}$ (II) isotopologues.

\begin{tabular}{lccc}
\hline Species & $E\left({ }^{206} \mathrm{~Pb}\right)($ a.u. $)$ & $E\left({ }^{207} \mathrm{~Pb}\right)($ a.u. $)$ & $E\left({ }^{208} \mathrm{~Pb}\right)($ a.u. $)$ \\
\hline $\mathrm{Pb}^{0}$ & -20913.809914518 & -20913.802358242 & -20913.790929932 \\
$\mathrm{~Pb}^{2+}$ & -20913.040069792 & -20913.032513369 & -20913.021084835 \\
$\mathrm{PbO}$ & -20988.661517728 & -20988.653961531 & -20988.642533338 \\
$\mathrm{PbCl}^{+}$ & -21374.555114672 & -21374.547558360 & -21374.536129993 \\
$\mathrm{~Pb}\left(\mathrm{H}_{2} \mathrm{O}\right)^{2+}$ & -20989.191326323 & -20989.183769909 & -20989.172341391 \\
\hline
\end{tabular}


Table 4. Nuclear field shift effects of $\mathrm{Pb}$ species compared to $\mathrm{Pb}^{2+}$.

\begin{tabular}{lcc}
\hline Species & $\begin{array}{c}10^{3} \ln K_{\text {fs }} \\
\left({ }^{207} \mathrm{~Pb}\right)\end{array}$ & $\begin{array}{c}10^{3} \ln K_{\mathrm{fs}} \\
\left({ }^{208} \mathrm{~Pb}\right)\end{array}$ \\
\hline $\mathrm{Pb}^{0}$ & 0.156 & 0.393 \\
$\mathrm{PbO}$ & 0.239 & 0.601 \\
$\mathrm{PbCl}$ & 0.118 & 0.295 \\
$\mathrm{~Pb}\left(\mathrm{H}_{2} \mathrm{O}\right)^{2+}$ & 0.010 & 0.026 \\
\hline
\end{tabular}

nuclear field shift is the possible origin of $\mathrm{Pb}$ isotope fractionation in our ligand exchange system. Since $\delta^{m} \mathrm{~Pb}$ is positive at smaller [HCl] (Fig. 3), the ln $K_{\mathrm{fs}}$ value for ${ }^{m} \mathrm{PbLCl}_{2}$ would be larger than that for ${ }^{m} \mathrm{PbCl}_{2}$. With the increase of acidity, the ligand exchange reaction of $\mathrm{H}_{2} \mathrm{O}$ by $\mathrm{Cl}^{-}$proceeds. According to $\ln K_{\mathrm{fs}}$ shown in Table 4, the promotion of this ligand exchange reaction depresses the $\delta^{m} \mathrm{~Pb}$ value observed. The acidity dependence of $\delta^{m} \mathrm{~Pb}$ shown in Fig. 3 may be hence attributable to the nuclear field shift effects between $\mathrm{PbCl}_{n}\left(\mathrm{H}_{2} \mathrm{O}\right)_{6-n}{ }^{2-n}$ species in the aqueous phase and their mole fractions.

\section{Conclusions}

Lead isotopes were fractionated in the ligand exchange reaction with DC18C6. $\delta^{m} \mathrm{~Pb}$ observed resulted from the intramolecular vibrations and the nuclear field shift effect. The conventional mass-dependent isotope fractionation estimated by the DFT calculation was smaller than the experimental results. The nuclear field shift effect was estimated by the $a b$ initio method including a finite nuclear model. The magnitude of nuclear field shift effect calculated covered $\delta^{m} \mathrm{~Pb}$ experimentally obtained. Therefore, the nuclear field shift effect is most probable origin of $\mathrm{Pb}$ isotope fractionation in the ligand exchange system.

Acknowledgment. TF, FM, and AA thank Francis Albarède, Emmanuelle Albalat, and Janne Blichert-Toft for their supports in experimental and theoretical investigations at the early stages of this work. TF thanks Roy Jacobus for his help in improving the English of this paper. AA is thankful to the Conseil Régional de Bretagne for its financial support. FM acknowledges support from NASA LASER \#NNX09AM64G.

\section{References}

1. Faure, G., Mensing, M. T.: Isotopes. Principles and Applications. John Wiley \& Sons, New Jersey (2005).

2. Urey, H. C.: The thermodynamic properties of isotopic substances. J. Chem. Soc. 562 (1947).

3. Bigeleisen, J., Mayer, M. G.: Calculation of equilibrium constants for isotopic exchange reactions. J. Chem. Phys. 15, 261 (1947).

4. Bigeleisen, J.: History and theory of uranium isotope enrichment by chemical exchange. Bull. Res. Lab. Nucl. React. 16(Special Issue 1), 3 (1992).

5. Bigeleisen, J.: Nuclear size and shape effects in chemical reactions. Isotope chemistry of the heavy elements. J. Am. Chem. Soc. 118, 3676 (1996).

6. Nomura, M., Higuchi, N., Fujii, Y.: Mass dependence of uranium isotope effects in the U(IV)-U(VI) exchange reaction. J. Am. Chem. Soc. 118, 9127 (1996).

7. Schauble, E. A.: Role of nuclear volume in driving equilibrium stable isotope fractionation of mercury, thallium, and other very heavy elements. Geochim. Cosmochim. Acta 71, 2189 (2007).

8. Abe, M., Suzuki, T., Fuji, Y., Hada, M.: An ab initio study based on a finite nucleus model for isotope fractionation in the U(III)-
(IV) exchange reaction system. J. Chem. Phys. 128, 144309 (2008).

9. Abe, M., Suzuki, T., Fujii, Y., Hada, M., Hirao, K.: An ab initio molecular orbital study of the nuclear volume effects in uranium isotope fractionations. J. Chem. Phys. 129, 164309 (2008).

10. Fujii, T., Moynier, F., Albarède, F.: The nuclear field shift effect in chemical exchange reactions. Chem. Geol. 267, 139 (2009).

11. Fujii, T., Moynier, F., Albarède, F.: Nuclear field vs nucleosynthetic effects as cause of isotopic anomalies in the early solar system. Earth Planet. Sci. Lett. 247, 1 (2006).

12. Bergquist, B. A., Blum, J. D.: Mass-dependent and -independent fraction of $\mathrm{Hg}$ isotopes by photoreduction in aquatic systems. Science 318, 417 (2007).

13. Jepson, B. E., DeWitt, R.: Separation of calcium isotopes with macrocyclic polyether calcium complex. J. Inorg. Nucl. Chem. 38, 1175 (1976).

14. Tsuvadze, A. Yu., Zhilov, V. I., Demin, S. V.: Isotope separation with macrocyclic polyethers. Russ. J. Coord. Chem. 22, 229 (1996).

15. Fujii, T., Moynier, F., Telouk, P., Albarède, F.: Nuclear field shift effect in the isotope exchange reaction of cadmium using a crown ether. Chem. Geol. 267, 157 (2009).

16. Frisch, M. J., Trucks, G. W., Schlegel, H. B., Scuseria, G. E., Robb, M. A., Cheeseman, J. R., Montgomery Jr., J. A., Vreven, T., Kudin, K. N., Burant, J. C., Millam, J. M., Iyengar, S. S., Tomasi, J., Barone, V., Mennucci, B., Cossi, M., Scalmani, G., Rega, N., Petersson, G. A., Nakatsuji, H., Hada, M., Ehara, M., Toyota, K., Fukuda, R., Hasegawa, J., Ishida, M., Nakajima, T., Honda, Y., Kitao, O., Nakai, H., Klene, M., Li, X., Knox, J. E., Hratchian, H. P., Cross, J. B., Adamo, C., Jaramillo, J., Gomperts, R., Stratmann, R. E., Yazyev, O., Austin, A. J., Cammi, R., Pomelli, C., Ochterski, J. W., Ayala, P. Y., Morokuma, K., Voth, G. A., Salvador, P., Dannenberg, J. J., Zakrzewski, V. G., Dapprich, S., Daniels, A. D., Strain, M. C., Farkas, O., Malick, D. K., Rabuck, A. D., Raghavachari, K., Foresman, J. B., Ortiz, J. V., Cui, Q., Baboul, A. G., Clifford, S., Cioslowski, J., Stefanov, B. B., Liu, G., Liashenko, A., Piskorz, P., Komaromi, I., Martin, R. L., Fox, D. J., Keith, T., AlLaham, M. A., Peng, C. Y., Nanayakkara, A., Challacombe, M., Gill, P. M. W., Johnson, B., Chen, W., Wong, M. W., Gonzalez, C., Pople, J. A.: Gaussian 03, Revision 6.1, Gaussian, Inc., Pittsburgh, PA (2003).

17. Becke, A. D.: Density-functional thermochemistry. 3. The role of exact exchange. J. Chem. Phys. 98, 5648 (1993).

18. Lee, C. T., Yang, W. T., Parr, R. G.: Development of the collesalvetti correlation-energy formula into a functional of the electron-density. Phys. Rev. B 37, 785 (1988).

19. Küchle, W., Dolg, W. M., Stoll, H., Preuss, H.: Ab initio pseudopotentials for $\mathrm{Hg}$ through $\mathrm{Rn}$. I. Parameter sets and atomic calculations. Mol. Phys. 74, 1245 (1991).

20. Gourlaouen, C., Gérard, H., Parisel, O.: Exploring the hydration of $\mathrm{Pb}^{2+}$. Ab initio studies and first-principles molecular dynamics. Chem. Eur. J. 12, 5024 (2006).

21. Noro, T., Sekiya, M., Osanai, Y., Miyoshi, E., Koga, T.: Relativistic correlating basis sets for the main group elements from Cs to Ra. J. Chem. Phys. 119, 5142 (2003).

22. The UTChem program package is available at http://utchem.qcl.t. u-tokyo.ac.jp/.

23. Faegri, K.: Relativistic Gaussian basis sets for the elements KUuo. Theo. Chem. Acc. 105, 252 (2001).

24. Tsuchiya, T., Abe, M., Nakajima, T., Hirao, K.: Accurate relativistic Gaussian basis sets for $\mathrm{H}$ through $\mathrm{Lr}$ determined by atomic self-consistent field calculations with the third-order DouglasKroll approximation. J. Chem. Phys. 115, 4463 (2001).

25. Roos, B. O., Lindh, R., Malmqvist, P.-Å., Veryazov, V., Widmark, P. -O.: New relativistic ANO basis sets for transition metal atoms. J. Phys. Chem. A 109, 6575 (2005).

26. Koc, K., Ishikawa, Y.: Single-fock-operator method for matrix Dirac-Fock self-consistent-field calculations on open-shell atoms. Phys. Rev. A 49, 794 (1994).

27. Zelić, M., Branica, M.: Influence of anion-induced adsorption on the polarographic/voltammetric determination of stability constants. Anal. Chim. Acta 268, 275 (1992).

28. King, W. H.: Isotope Shifts in Atomic Spectra. Plenum Press, New York (1984). 
29. Li, J., Fisher, C. L., Chen, J. L., Bashford, D., Noodleman, L.: Calculation of redox potentials and $\mathrm{p} K_{\mathrm{a}}$ values of hydrated transition metal cations by a combined density functional and continuum dielectric theory. Inorg. Chem. 35, 4694 (1996).

30. Rosseinsky, D. R.: Electrode potentials and hydration energies. Theories and correlations. Chem. Rev. 65, 467 (1965).
31. Smith, D. W.: Ionic hydration enthalpies. J. Chem. Edu. 54, 540 (1977).

32. Marcus, Y.: Ion Solvation. John Wiley \& Sons, New York (1985).

33. Angeli, I.: A consistent set of nuclear rms charge radii. Properties of the radium surface $R(N, Z)$. Atomic Data Nucl. Data Tables 87, 185 (2004). 